\title{
Is Local Anesthetic Infiltration Prior to Intravenous Cannulation Beneficial to Patients?
}

\author{
Shrestha BR, ${ }^{1}$ Shrestha $\mathbf{U}^{1}$ Shrestha $A,{ }^{1}$ Rana $\mathbf{A}^{1}$ \\ ${ }^{1}$ Department of Anesthesiology, Kathmandu Medical College Teaching Hospital, Kathmandu, Nepal.
}

\begin{abstract}
Aims: Intravenous cannulation causes pain, anxiety and frustration in patients along with changes in hemodynamic parameters. Infiltration of local anesthetic lessens the pain of intravenous cannulation. This study was performed to compare cardiovascular responses and verbal rating pain scores in two groups with and without local anesthetic infiltration prior to venous cannulation.
\end{abstract}

Methods: This was a randomized study conducted in 100 elective surgical patients, divided into two study groups with 50 patients in each: group A (Control) and group B (local anesthetic infiltration). Prior to venous cannulation in group B, $0.5 \mathrm{ml}$ of $1 \%$ lidocaine was infiltrated at the procedure site at dorsum of the wrist. Patients in group A were cannulated directly without local anesthetic infiltration. The hemodynamic changes pre and post cannulation and verbal pain rating scores were recorded by blind observers in all patients.

Results: Demographic values in two groups were similar. Increase in heart rate from baseline value was significant in control group (p $<$ 0.05). Post cannulation heart rate, systolic and diastolic blood pressure were significantly higher in group A compared to group B for the first three minutes $(p<0.05)$. Amongst higher number of patients in group A, verbal rating pain score was significantly higher. Ninety-four percent of the patients in group B were pain free, comfortable and satisfied with the procedure.

Conclusions: Intravenous cannulation can be made pain free with patient satisfaction and hemodynamic stability if carried out with prior local anesthetic infiltration.

Keywords: hemodynamics, infiltration, local anesthetic, pain, venous cannulation.

\section{INTRODUCTION}

Venous access is an integral part of patient care in hospitals. Intravenous cannulation (IVC) is a painful and stressful procedure, which may cause sympathetic stimulation or even vaso-vagal reaction due to pain and anxiety.

Most of the time pain is a widely underestimated health issue, especially while performing intravenous cannulation. Untreated or inadequately treated pain, caused by IVC leads to patient dissatisfaction and adds hazards, particularly to hypertensive and cardiac comorbid patients. Thus, reducing pain of IVC may contribute

\section{CORRESPONDENCE}

Dr Babu Raja Shrestha

Department of Anesthesiology, Kathmandu Medical College Teaching Hospital, Kathmandu, Nepal.

Email: barashrestha@yahoo.co.in

Phone: 9851044526 to patients' perceived satisfaction. To find out how much comfort our patients can achieve during IVC preceded by local anesthetic infiltration, we designed this study in elective surgical patients at Kathmandu Medical College.

The objectives of this study were to compare cardiovascular responses, determine verbal pain rating scale and satisfaction score in patients undergoing IVC with or without local anesthetic infiltration.

The papers in this journal are published under the terms of the Creative Commons Attribution License. Users are allowed to read, download, copy, distribute, print, search, or link to the full texts of the articles in this journal without asking prior permission from the publisher or the author. 


\section{METHODS}

Hundred elective surgical patients from American Society of Anesthesiologists (ASA) physical status I-II, aged 20-60 years and weighing $45-75 \mathrm{Kg}$ were recruited in the study. Those patients with venous canula in situ, having invisible bad veins even after tourniquet application, with local hematoma at the site of cannulation, having more than one cannulation attempt and on beta-blocker therapy were excluded. Patients were randomly allocated to group A (control) and group B (local anesthetic infiltration group), each having 50 patients, by using lottery technique. All patients were premedicated with tablet metoclopramide $10 \mathrm{mg}$ and tab diazepam $5 \mathrm{mg}$ the night before surgery. Baseline heart rate (HR) and blood pressure (BP) of all patients were recorded just before venepuncture with the 18 gauge intravenous cannula. Patients from group $B$ had infiltration with $0.5 \mathrm{ml}$ of $1 \%$ lidocaine at the dorsum of the wrist with $27 \mathrm{G}$ insulin syringe at the site of cannulation one minute prior to IVC. HR and BP were recorded at different time points at one, two and three minute postcannulation.

The patients were interviewed immediately following the procedure to rate the pain/discomfort they felt during cannulation according to the verbal ratings of pain with four categories: comfortable, mild discomfort, painful and very painful. Following the procedure, patients were asked how they liked the procedure. Patients were classified as satisfied if they would say they had not felt any pain or just mild discomfort. The rest would belong to unsatisfied group if they complained of painful or very painful cannulation and were frustrated about the technique.

Systolic (SBP), diastolic blood pressure (DBP) and heart rates were presented as mean \pm SD (standard deviation). Data were analyzed by Student's t-test for unpaired observations. ANOVA test was applied to compare the changes in SBP, DBP and HR values. A probability of less than 0.05 was considered statistically significant. The statistical package SPSS 14.0 (SPSS ${ }^{\circledR}$ Inc., Chicago, IL, USA) was used.

\section{RESULTS}

There were no statistical differences among the groups in age, weight and gender (Table 1). The case distribution was similar in both the groups (Table 2). Four patients from group $A$ and two from group $B$ were withdrawn from the study because of inability to cannulate due to more than one attempt and deformed local anatomy after hematoma.
Table 1. Demography of patients in two groups.

\begin{tabular}{llll}
\hline Group & $\begin{array}{l}\text { Age } \\
\text { (years) }\end{array}$ & Sex & $\begin{array}{l}\text { Weight } \\
\text { (kilograms) }\end{array}$ \\
\hline Control A & $42 \pm 3.70$ & $\mathrm{~F}=35, \mathrm{M}=11$ & $58 \pm 9.02$ \\
LA infiltration B & $44 \pm 6.42$ & $\mathrm{~F}=40, \mathrm{M}=8$ & $61 \pm 13.16$ \\
p-value & 0.201 & & 0.310 \\
\hline
\end{tabular}

Table 2. Case distribution by specialities.

\begin{tabular}{lllll}
\hline Group & $\begin{array}{l}\text { General } \\
\text { surgery }\end{array}$ & $\begin{array}{l}\text { Obstetrics/ } \\
\text { Gynecology }\end{array}$ & Orthopedics & ENT \\
\hline Control A & 7 & 33 & 3 & 3 \\
LA & 7 & 35 & 4 & 2 \\
infiltration B & & & & \\
\hline
\end{tabular}

There was a significant rise in blood pressure, both SBP and DBP, one minute following cannulation in group $A$, $p$-value being 0.03 and 0.01 respectively (Tables 3 and 4). There was significant difference in $\mathrm{HR}$ in the subsequent two minutes after cannulation, with HR being higher in group A (Table 5).

Table 3. Systolic blood pressure $(\mathrm{mm}$ of $\mathrm{Hg}$ ) at different time points in two groups.

\begin{tabular}{lllll}
\hline Group & Baseline & $\begin{array}{l}\text { One min } \\
\text { post } \\
\text { cannulation }\end{array}$ & $\begin{array}{l}\text { Two min } \\
\text { post } \\
\text { cannulation }\end{array}$ & $\begin{array}{l}\text { Three } \\
\text { min post } \\
\text { cannulation }\end{array}$ \\
\hline $\begin{array}{l}\text { Control } \\
\text { A }\end{array}$ & $113 \pm 13.21$ & $126 \pm 14.62$ & $122 \pm 10.22$ & $119 \pm 11.30$ \\
$\begin{array}{l}\text { LA } \\
\text { infiltration B }\end{array}$ & $117 \pm 9.28$ & $113 \pm 11.10$ & $117 \pm 13.20$ & $116 \pm 10.91$ \\
p-value & 0.124 & 0.031 & 0.062 & 0.120 \\
\hline
\end{tabular}

Table 4. Diastolic blood pressure $(\mathrm{mm} \mathrm{Hg})$ at different time points in two groups.

\begin{tabular}{lllll}
\hline Group & Baseline & $\begin{array}{l}\text { One min } \\
\text { post } \\
\text { cannulation }\end{array}$ & $\begin{array}{l}\text { Two min } \\
\text { post } \\
\text { cannulation }\end{array}$ & $\begin{array}{l}\text { Three } \\
\text { min post } \\
\text { cannulation }\end{array}$ \\
\hline Control A & $76 \pm 6.1$ & $84 \pm 3.8$ & $79 \pm 9.2$ & $75 \pm 7.1$ \\
LA infiltration B & $80 \pm 12.5$ & $69 \pm 10.0$ & $72 \pm 6.6$ & $73 \pm 11.4$ \\
p-value & 0.11 & 0.001 & 0.180 & 0.580 \\
\hline
\end{tabular}


Table 5. Heart rate per minute at different time points in two groups.

\begin{tabular}{llllll}
\hline Group & Baseline & $\begin{array}{l}\text { One min post } \\
\text { cannulation }\end{array}$ & $\begin{array}{l}\text { Two min post } \\
\text { cannulation }\end{array}$ & $\begin{array}{l}\text { Three min post } \\
\text { cannulation }\end{array}$ & $\begin{array}{l}\text { p-value } \\
\text { (intergroup) }\end{array}$ \\
\hline Control A & $83 \pm 9.85$ & $97 \pm 6.12$ & $95 \pm 10.55$ & $93 \pm 10.10$ & $<0.05$ \\
LA infiltration B & $85 \pm 11.01$ & $83 \pm 9.64$ & $84 \pm 10.02$ & $86 \pm 9.20$ & $>0.05$ \\
p-value (between groups) & 0.087 & 0.001 & 0.013 & 0.060 & \\
\hline
\end{tabular}

Response to IVC was assessed using verbal pain rating scale according to which in group A more patients complained of pain than in group $B$, which was statistically significant (Table 6).

Table 6. Number of patients having different verbal rating for pain.

\begin{tabular}{lcccc}
\hline Group & $\begin{array}{l}\text { No pain } \\
\text { (comfortable) }\end{array}$ & $\begin{array}{l}\text { Mild } \\
\text { pain }\end{array}$ & Painful & $\begin{array}{l}\text { Very } \\
\text { Painful }\end{array}$ \\
\hline $\begin{array}{l}\text { Control A } \\
(n=46)\end{array}$ & 0 & $13 \%$ & $59 \%$ & $28 \%$ \\
$\begin{array}{l}\text { LA } \\
\text { infiltration B } \\
(n=48)\end{array}$ & $85.4 \%$ & $12.5 \%$ & $2.1 \%$ & 0 \\
p-value & 0.000 & 0.250 & 0.000 & 0.003 \\
\hline
\end{tabular}

A significantly increased number of patients who received local anesthetic prior to venous cannulation were satisfied with the procedure ( $98 \%$ in Group B vs $13 \%$ in Group A) \{Table 7\}.

Table 7. Patient satisfaction of the cannulation procedure.

\begin{tabular}{lll}
\hline Group & Satisfied & Not satisfied \\
\hline Control A & $6(13 \%)$ & $40(87 \%)$ \\
LA infiltration B & $47(98 \%)$ & $1(2 \%)$ \\
p-value & 0.011 & 0.000 \\
\hline
\end{tabular}

\section{DISCUSSION}

Our findings showed that local anesthetic infiltration prior to intravenous cannulation was more effective to reduce pain and provide patient satisfaction and initial hemodynamic stability after the procedure.

The selection of the age group of patients in the current study was based on the fact that the patients of extreme age group may not respond to the questionnaires efficiently. Also, the pain score was not categorized according to sex distribution. However, both the groups predominantly had female patients and the number of the patients were similar. A study has shown that there is difference in pain perception in male and female patients during IVC. ${ }^{1}$
IVC is a painful procedure which increases sympathetic stimulation causing increased heart rate and blood pressure, both systolic and diastolic, which was evidenced by the present study. The hemodynamic surge was mainly noticed during initial first minute post cannulation.Though the effect was short-lived, the values were meaningful and hold statistical significance. This finding is consistent with the study conducted by Rohm KD et $\mathrm{al}^{2}$ who observed significant pressure response to venous cannulation which was obtunded by prior infiltration with local anesthetic. Similar results were also found in different studies and hemodynamic consistency was observed with local anesthetic infiltration at cannulation site before IVC. ${ }^{3-6}$ According to Langham BT et al, ${ }^{7}$ a $10-15 \%$ rise in mean arterial pressure after IVC can be abolished by intradermal injection of local anesthetic. The pain of IVC is sharp, but remains for a short period of time. This could be the reason why the cardiovascular parameters noticed in this study persisted only for a limited period of time. This acute increase in hemodynamic values may not be desirable in cardiac co-morbid patients.

It is understood that in emergency situations one may not have sufficient time to wait for the effect of local anesthetic infiltration, but in routine surgical cases or in wards, this method can be employed as it gives much satisfaction to patients by reducing pain. This increases patients' acceptability of our invasive procedure. There is a study employing this technique to minimize pain of IVC right in the emergency department. ${ }^{8}$

In this study the five point verbal rating of pain ${ }^{9}$ was modified to four point scale for convenience to our general population during post procedural interviewing to minimize the number of questions to them and get the answers straight ahead. We found the four point verbal rating scale adopted in this current research was more convenient and comfortable to both patients and clinicians alike. Majority of patients in group B (98\%) were satisfied and took the procedure very easily as they did not feel any pain due to prior infiltration of the site with local anaesthetic. Larger catheter gauge was correlated with greater pain during cannulation. ${ }^{10,11}$ It is recommended to give local anesthetic infiltration only if cannula size is equal to or greater than $16 \mathrm{G}$. The vast majority of patients and health care workers would prefer to have local anesthetic infiltration for IVC even with a $22 \mathrm{G}$ needle. ${ }^{12}$ The median pain scores for catheter insertion in the forearm were higher than scores for either the hand or wrist. ${ }^{1,11}$ The site 
for IVC in our study was dorsum of the wrist and the size of cannula remained the same for all patients in our study as change in these factors may affect the pain scores as documented by the study. ${ }^{1}$ The size of veins cannulated might differ from one patient to another. The age, body weight and physique may play a role in this regard. The age and body weight of patients in the study groups were similar. Obese patients may predispose difficulty in IVC. In a study by Holdgate et al ${ }^{13}$, they found subcutaneous lidocaine did not significantly affect the success rate of IVC on the first attempt and support the use of local anesthetic infiltration for all routine venous cannulation. There is a concern that the local anesthetic infiltration may distort the puncture site and obscure the veins, but this may be prevented by using $0.3-0.5 \mathrm{ml}$ of the agent which quickly dissipates from the site.

There are various methods to reduce pain and anxiety of IVC by applying eutectic mixture of local anesthetics (EMLA) cream at the puncture site ${ }^{14}$ or preoperative use of oral clonidine, an alpha ${ }_{2}$ agonist, during pre-anesthetic visit for this purpose. ${ }^{15}$ Both these agents are not available in our setup. Lidocaine infiltration is a simple and noble technique to be adopted. Cultivating this habit prior to venous cannulation definitely improves patient satisfaction at no added cost.

\section{CONCLUSIONS}

Local anesthetic infiltration with lidocaine at the site of venous cannulation significantly reduced pain and gave maximum patient satisfaction without causing hemodynamic stress during the procedure.

\section{REFERENCES}

1. Van Der Berg AA, Abeysekera RM. Rationalising venous cannulation: patient factors and lignocaine efficacy. Anaesthesia. 1993;48:84.

2. Rohm KD, Schollhorn TA, Gwosdek MJ, Piper SN. Do we necessarily need local anaesthetics for venous cannulation? A comparison of different cannula sizes. Eur J Anaesthesiol. 2004;21:214-6.
3. Paton RH. Local anaesthesia and venous cannulation. Anaesthesia. 1995;50:1005-6.

4. Giner J, Casan P, Belda J, Gonzalez M, Miralda RM, Sanchis J. Pain during arterial puncture. Chest. 1996;110:1443.

5. Ong EL, Lim NL, Koay CK. Towards a pain free venepuncture. Anaesthesia. 2000;55:260-2.

6. Nuttall GA, Barnett MR, Smith RL, Blue TK, Clark KR, Payton BW. Establishing intravenous access: a study of local anesthetic efficacy. Anesth Analg. 1993 Nov;77(5):950-3.

7. Langham BT, Harrison DA. The pressor response to venous cannulation: attenuation by prior infiltration with local anaesthetic. Br J Anaesth. 1993;70:519-21.

8. Harris T, Cameron PA, Ugoni A. The use of pre cannulation local anaesthetic and factors affecting pain perception in the emergency department setting. Emergency Med J. 2001;18: 175-7.

9. Cannell $\mathrm{H}$. Evidence for safety margins of lignocaine local anaesthetics for peri-oral use. Br Dent J. 1996;181(7):243-9.

10. Langham BT, Harrison DA. Local anaesthetic: does it really reduce the pain of insertion of all sizes of venous cannula? Anaesthesia. 1992;47:890-1.

11. Brown D. Local anesthesia for vein cannulation. J Infusion Nurs. 2004;27:85-8.

12. Valdovinos NC, Christopher R, Cynthia R, Brooke S, Paula T. The use of topical anesthesia during intravenous catheter insertion in adults: a comparision of pain scores using LMX-4 versus placebo. J Emerg Nurs. 2009;35:299-304.

13. Holdgate A, Wong G. Does local anaesthetic affect the success rate of intra venous cannulation? Anaesth Intens Care. 1999;27: 257-9.

14. Soliman IE. Comparison of the analgesic effects of EMLA (eutectic mixture of local anesthetics) to intradermal lidocaine infiltration prior to venous cannulation in unpremedicated children. Anesthesiology. 1988;68:804-6.

15. Hall DL, Rezvan E, Tatakis DN, Walters JD. Oral clonidine pretreatment prior to venous cannulation. Anesth Prog. 2006;53(2):34-42. 